Journal of Patient-Centered

4-19-2021

\title{
Prevalence of Common Disease Conditions in a Large Cohort of Individuals With Down Syndrome in the United States
}

\author{
Brian Chicoine \\ Anne Rivelli \\ Veronica Fitzpatrick \\ Laura Chicoine \\ Gengjie Jia \\ Andrey Rzhetsky
}

Follow this and additional works at: https://aah.org/jpcrr

Part of the Clinical Epidemiology Commons, Congenital, Hereditary, and Neonatal Diseases and Abnormalities Commons, Disability Studies Commons, Family Medicine Commons, and the Other Medical Specialties Commons

\section{Recommended Citation}

Chicoine B, Rivelli A, Fitzpatrick V, Chicoine L, Jia G, Rzhetsky A. Prevalence of common disease conditions in a large cohort of individuals with Down syndrome in the United States. J Patient Cent Res Rev. 2021;8:86-97. doi: 10.17294/2330-0698.1824

Published quarterly by Midwest-based health system Advocate Aurora Health and indexed in PubMed Central, the Journal of Patient-Centered Research and Reviews (JPCRR) is an open access, peer-reviewed medical journal focused on disseminating scholarly works devoted to improving patient-centered care practices, health outcomes, and the patient experience. 


\title{
Prevalence of Common Disease Conditions in a Large Cohort of Individuals With Down Syndrome in the United States
}

\author{
Brian Chicoine, MD, ${ }^{1,3}$ Anne Rivelli, MPH, MA, ${ }^{1,2}$ Veronica Fitzpatrick, DrPH, ${ }^{1,2}$ Laura Chicoine, BA, ${ }^{1,3}$ \\ Gengjie Jia, PhD, ${ }^{4,5}$ Andrey Rzhetsky, $\mathrm{PhD}^{4,5}$ \\ ${ }^{1}$ Advocate Aurora Health, Downers Grove, IL; ${ }^{2}$ Advocate Aurora Research Institute, Downers Grove, IL; ${ }^{3}$ Advocate \\ Medical Group Adult Down Syndrome Center, Park Ridge, IL; ${ }^{4}$ Department of Medicine, University of Chicago, \\ Chicago, IL; ${ }^{5}$ Institute of Genomics and Systems Biology, University of Chicago, Chicago, IL
}
Purpose Given the current life expectancy and number of individuals living with Down syndrome (DS), it is important to learn common occurrences of disease conditions across the developmental lifespan. This study analyzed data from a large cohort of individuals with DS in an effort to better understand these disease conditions, inform future screening practices, tailor medical care guidelines, and improve utilization of health care resources.
Methods This retrospective, descriptive study incorporated up to 28 years of data, compiled from 6078 individuals with DS and 30,326 controls matched on age and sex. Data were abstracted from electronic medical records within a large Midwestern health system.

Results In general, individuals with DS experienced higher prevalence of testicular cancer, leukemias, moyamoya disease, mental health conditions, bronchitis and pneumonia, gastrointestinal conditions, thyroid disorder, neurological conditions, atlantoaxial subluxation, osteoporosis, dysphagia, diseases of the eyes/adnexa and of the ears/mastoid process, and sleep apnea, relative to matched controls. Individuals with DS experienced lower prevalence of solid tumors, heart disease conditions, sexually transmitted diseases, HIV, influenza, sinusitis, urinary tract infections, and diabetes. Similar rates of prevalence were seen for lymphomas, skin melanomas, stroke, acute myocardial infarction, hepatitis, cellulitis, and osteoarthritis.

Conclusions While it is challenging to draw a widespread conclusion about comorbidities in individuals with Down syndrome, it is safe to conclude that care for individuals with DS should not automatically mirror screening, prevention, or treatment guidelines for the general U.S. population. Rather, care for those with DS should reflect the unique needs and common comorbidities of this population. ( $J$ Patient Cent Res Rev. 2021;8:86-97.)

Keywords Down syndrome; epidemiology; comorbidities; family medicine; population health

$\mathrm{D}$ own syndrome (DS) is the most frequent chromosomal abnormality among live-born infants and the most common genetic cause of intellectual disability in the world. ${ }^{1,2}$ Due to improved screening and advances in medical technology and care, the lifespan for an individual with DS has more than doubled to age 60 in the past few decades. ${ }^{3-7}$ Recent U.S.-based population estimates of major birth defects

Corresponding author: Veronica Fitzpatrick, DrPH, Advocate Lutheran General Hospital, 1775 Dempster Street, W-939, Park Ridge, IL 60068 (veronica.fitzpatrick@aah.org) concluded that, while prevalence of most birth defects has remained stable over the past 15 years, prevalence of DS is increasing. ${ }^{8}$ With increasing prevalence and longer lifespans of individuals with DS, it is important to understand common occurrences of co-occurring conditions, or comorbidities, across the developmental lifespan for more appropriate screening practices, tailored medical care guidelines, improved utilization of health care resources, and up-to-date planning and management of care for individuals with DS.

Individuals with DS represent a unique population in need of health care guidelines that address their specific medical care. ${ }^{9-13}$ A high prevalence of comorbidity has been documented among adults with DS, with types 
and patterns that differ from the general population; ${ }^{11,13}$ specifically, individuals with DS experience lower prevalence of many solid tumors ${ }^{14}$ and many cardiovascular issues, particularly atherosclerosis, hypertension, and acute myocardial infarction ${ }^{15}$ as well as coronary heart disease and heart failure. ${ }^{16} \mathrm{On}$ the contrary, individuals with DS experience higher prevalence of stroke, ${ }^{15}$ endocrine disorders (eg, diabetes $),{ }^{15}$ thyroid disorders, ${ }^{17}$ Alzheimer's disease, ${ }^{18}$ sleep apnea, ${ }^{15,19}$ and leukemia. ${ }^{20}$ Most of this literature comes from countries with vastly different demographics and medical care that routinely track health conditions in centralized, linked databases or registries; however, comprehensive comorbidity data on individuals with DS within the United States is still lacking.

Comorbidity in general requires complex medical management, but care complexity is compounded for those with DS by limitations in communication and understanding. ${ }^{13}$ Furthermore, the United States' noncentralized, nonstandardized, and on-demand record system results in fragmented information that is often difficult for health care providers to share for more consistent care. $^{21,22}$ Most individuals with DS receive their care in settings that do not specialize in DS care and are subsequently less familiar with common comorbidities and the unique needs of this group. ${ }^{9,10}$ These issues create barriers to consistent and comprehensive care for individuals with DS. They also hinder national research documenting comorbidities specific to individuals with DS. Guidelines for youth with DS recommend that parents become experts of DS in order to best support medical care for their children; ${ }^{23}$ however, more widely available U.S.-based literature would help guide providers and better inform individuals with DS as they continue to age and support their own care.

Evidence-based clinical guidelines for primary care of adults with DS were very recently published, ${ }^{24}$ but U.S.-based research on comorbidity prevalence could complement the guidelines and fill a significant gap in the literature. ${ }^{9,10,24}$ Providing critical information on conditions unique to individuals with DS in the United States may better guide general practitioners and enhance specialized care for DS. The clinical data set used in this study represents the largest sample of individuals with DS in the United States to date. Patients were treated across a single Midwestern health system that includes the largest U.S. center of care for adults with DS. The study aims to document prevalence of a broad range of comorbidities in individuals with DS and provide relative comparisons to age- and sex-matched individuals without DS.

\section{METHODS}

This retrospective, descriptive cohort study utilized 28 years of available encounter data abstracted from electronic medical records collected from all sites within a large Midwestern nonprofit health system. The system included 10 acute care hospitals, including 2 children's hospitals, a specialty hospital for extended care needs, 3 large medical groups, and comprehensive home health and hospice services to serve the greater metropolitan area of a populous city. The study was determined to be non-human subjects research by the Advocate Aurora Health institutional review board.

\section{Participants}

For study inclusion, cases were identified using the International Classification of Diseases (ICD)9, diagnosis code of 758.0 ("Down syndrome") or equivalent ICD-10 diagnosis codes of Q90 ("Down syndrome"), Q90.0 ("Trisomy 21, nonmosaicism [meiotic nondisjunction]"), Q90.1 ("Trisomy 21, mosaicism [mitotic nondisjunction]"), Q90.2 ("Trisomy 21, translocation"), or Q90.9 ("Down syndrome, unspecified") in the electronic medical records. A data analyst identified 6078 eligible cases based on at least one encounter with an ICD code of DS. All 68,299 case encounters in the health system, prior to and after the DS diagnosis code, were reviewed for this study.

Controls included up to 5 individuals without a diagnosis of DS identified and matched to each case on year of birth ( \pm 1 year) and sex by the data analyst. The analyst identified 30,326 eligible controls. All 341,716 control encounters in the health system were reviewed for this study; 64 cases had only 4 matched controls.

\section{Procedures}

This study preidentified specific conditions of interest to assess prevalence among individuals with DS compared to individuals without DS. Conditions were chosen based on literature and clinical expertise. A coding system of ICD-9 diagnosis codes developed as part of the Healthcare Cost and Utilization Project, sponsored by the Agency for Health Research and Quality (AHRQ), was used to represent the conditions of interest. The coding system, the Clinical Classifications Software (CCS) for ICD-9, is one of a family of databases and software tools designed to be employed in projects analyzing diagnosis data. The AHRQ CCS collapsed ICD-9 codes into clinically meaningful categories that are more useful for presenting descriptive statistics of clinical conditions than are individual ICD-9 codes. ${ }^{25} \mathrm{~A}$ few conditions of interest did not align with AHRQ CCS categories and, instead, were assigned ICD-9 codes by the research team. Table $1^{25}$ provides a complete list 
Table 1. Conditions of Interest and Associated Codes

\begin{tabular}{|c|c|}
\hline Conditions & Codes $^{25}$ \\
\hline $\begin{array}{l}\text { Cancer conditions } \\
\text { Breast } \\
\text { Cervix } \\
\text { Testis } \\
\text { Colorectal } \\
\text { Leukemia } \\
\text { Lymphoma (Hodgkin's and non-Hodgkin's) } \\
\text { Melanomas of skin }\end{array}$ & $\begin{array}{l}\text { AHRQ } 24 \\
\text { AHRQ } 26 \\
\text { AHRQ } 30 \\
\text { AHRQ 14-15 } \\
\text { AHRQ } 39 \\
\text { AHRQ } 37-38 \\
\text { AHRQ } 22\end{array}$ \\
\hline $\begin{array}{l}\text { Heart disease conditions } \\
\text { High blood pressure/hypertension } \\
\text { Late effects of cerebrovascular disease (stroke) } \\
\text { Coronary atherosclerosis and other heart disease } \\
\text { Acute myocardial infarction } \\
\text { Moyamoya }\end{array}$ & $\begin{array}{l}\text { AHRQ 98-99 } \\
\text { AHRQ } 113 \\
\text { AHRQ } 101 \\
\text { AHRQ } 100 \\
\text { ICD-9 } 4375\end{array}$ \\
\hline $\begin{array}{l}\text { Mental health conditions } \\
\text { Anxiety } \\
\text { Obsessive-compulsive disorder } \\
\text { Attention-deficit, conduct, disruptive behavior disorders } \\
\text { Mood disorders } \\
\text { Schizophrenia and other psychoses } \\
\text { Impulse control disorders, NEC } \\
\text { Catatonia }\end{array}$ & $\begin{array}{c}\text { AHRQ 651 } \\
\text { ICD-9 } 3003 \\
\text { AHRQ } 652 \\
\text { AHRQ } 657 \\
\text { AHRQ } 659 \\
\text { AHRQ } 656 \\
\text { ICD-9 } 78199,29389,2948\end{array}$ \\
\hline $\begin{array}{l}\text { Infections } \\
\text { Sexually transmitted diseases (not including HIV or hepatitis) } \\
\text { HIV } \\
\text { Hepatitis } \\
\text { Influenza } \\
\text { Bronchitis } \\
\text { Sinusitis } \\
\text { Pneumonia } \\
\text { Urinary tract infection } \\
\text { Cellulitis }\end{array}$ & $\begin{array}{c}\text { AHRQ } 9 \\
\text { AHRQ } 5 \\
\text { AHRQ } 6 \\
\text { AHRQ 123 } \\
\text { AHRQ 125 } \\
\text { ICD-9 461*, } 473^{*} \\
\text { AHRQ 122 } \\
\text { AHRQ 159 } \\
\text { ICD-9 681*-682* }\end{array}$ \\
\hline $\begin{array}{l}\text { Gastrointestinal conditions } \\
\text { Intestinal obstruction without hernia } \\
\text { Esophageal disorders } \\
\text { Gastroduodenal ulcer except hemorrhage } \\
\text { Celiac }\end{array}$ & $\begin{array}{l}\text { AHRQ } 145 \\
\text { AHRQ } 138 \\
\text { AHRQ } 139 \\
\text { ICD-9 } 5790\end{array}$ \\
\hline $\begin{array}{l}\text { Endocrine conditions } \\
\text { Thyroid } \\
\text { Diabetes }\end{array}$ & $\begin{array}{c}\text { AHRQ } 48 \\
\text { AHRQ 49-50 }\end{array}$ \\
\hline $\begin{array}{l}\text { Neurology conditions } \\
\text { Epilepsy; convulsions } \\
\text { Alzheimer's disease } \\
\text { Myelopathy, cervical }\end{array}$ & $\begin{array}{c}\text { AHRQ } 83 \\
\text { ICD-9 3310, } 2941^{*} \\
\text { ICD-9 } 7211,72271\end{array}$ \\
\hline $\begin{array}{l}\text { Orthopedic conditions } \\
\text { Atlantoaxial subluxation } \\
\text { Osteoporosis } \\
\text { Osteoarthritis }\end{array}$ & $\begin{array}{c}\text { ICD-9 83900-83902, 83910-83912 } \\
\text { AHRQ } 206 \\
\text { AHRQ } 203\end{array}$ \\
\hline $\begin{array}{l}\text { Miscellaneous conditions } \\
\text { Dysphagia } \\
\text { Diseases of the eyes and adnexa } \\
\text { Diseases of the ears and mastoid process } \\
\text { Sleep apnea }\end{array}$ & $\begin{array}{c}\text { ICD-9 } 7872^{*} \\
\text { ICD-9 360-379 } \\
\text { ICD-9 380-389 } \\
\text { ICD-9 32720-32721, 32723, 32727, } 32729\end{array}$ \\
\hline
\end{tabular}

Asterisks (*) indicate the full range of numbers were explored in this place.

AHRQ, Agency for Health Research and Quality; ICD-9, International Classification of Diseases, Ninth Revision; NEC, not elsewhere classified. 
of clinical conditions of interest and their associated AHRQ CCS categories or ICD-9 codes.

Study data consisted of all ICD-9 codes. All ICD-10 codes documented after October 1, 2015, were converted to ICD-9 codes by the study data analyst. Prevalence of clinical conditions was assessed by totaling unique cases and controls, respectively, with at least one AHRQ ICD-9 code in each category in any encounter. At least one ICD-9 code in an encounter indicated the condition represented by the category of codes was prevalent. Odds and odds ratios (OR) with 95\% confidence intervals were calculated across each clinical condition of interest.

Demographic factors, including age, total number of encounters, sex, race, ethnicity, and insurance, were assessed separately for cases and controls (Table 2). Odds, OR, and corresponding P-values were calculated to compare prevalence of conditions among cases (ie, individuals with DS) relative to matched controls (ie, individuals without DS) (Table 3).

\section{Statistical Methods}

Demographics are reported as means with standard deviations and medians with ranges for age and total encounters per sample. Sex, race, ethnicity, and insurance are reported as counts with percentages. Clinical conditions are reported as counts with percentages and corresponding OR representing the ratio of odds of cases having a comorbidity relative to controls. Corresponding P-values represent statistically significant differences between prevalence of diagnoses among cases relative to controls. Pearson's chi-squared $\mathrm{P}$-values were interpreted, except when any cell count was $<5$, in which case Fisher's exact test P-values were interpreted.

Data management and analysis of the DS sample were conducted with SAS 9.4 statistical software (SAS

Table 2. Demographics and Baseline Characteristics of Cases and Controls

\begin{tabular}{lccc}
\hline & $\begin{array}{c}\text { DS Sample } \\
(\mathbf{N = 6 0 7 8 )}\end{array}$ & $\begin{array}{c}\text { Control Sample } \\
(\mathbf{N}=30326)\end{array}$ & $\boldsymbol{P}$ \\
\hline Age in years, mean (SD) and median (IQR) & $27.88(20.37) ;$ & $29.04(20.96) ;$ & $<0.0001^{*}$ \\
& $25.00(9-46)$ & $25.00(11-48)$ & \\
Total encounters, mean (SD) and median (IQR) & $11.23(15.19) ;$ & $11.27(16.27) ;$ & 0.8440 \\
Sex & $6.00(2-14)$ & $7.00(3-13)$ & \\
Male & $\mathrm{n}=6075$ & $\mathrm{n}=30,324$ & \\
Female & $3171(52.19 \%)$ & $15,816(52.15 \%)$ & 0.9536 \\
Race & $2904(47.79 \%)$ & $14,508(47.84 \%)$ & \\
White & $\mathrm{n}=4495$ & $\mathrm{n}=21,296$ & \\
Black & $3477(77.35 \%)$ & $13,198(61.97 \%)$ & $<0.0001^{*}$ \\
Asian & $650(14.46 \%)$ & $6667(31.31 \%)$ & \\
American Indian & $150(3.34 \%)$ & $1183(5.56 \%)$ & \\
Other & $57(1.27 \%)$ & $174(0.82 \%)$ & \\
Ethnicity & $161(3.58 \%)$ & $74(0.35 \%)$ & \\
Hispanic & $\mathrm{n}=3212$ & $\mathrm{n}=21,066$ & \\
Non-Hispanic & $851(26.49 \%)$ & $3851(18.28 \%)$ & $<0.0001^{*}$ \\
Insurance & $2361(73.51 \%)$ & $17,215(81.72 \%)$ & \\
Private & $\mathrm{n}=5991$ & $\mathrm{n}=29,666$ & \\
Medicare & $2848(47.54 \%)$ & $22,532(75.95 \%)$ & $<0.0001^{*}$ \\
Medicaid & $2090(34.89 \%)$ & $1464(4.93 \%)$ & \\
Other & $644(10.75 \%)$ & $4097(13.82 \%)$ & \\
\hline
\end{tabular}

*Statistically significant per Pearson's chi-squared test.

$D S$, Down syndrome; IQR, interquartile range; $S D$, standard deviation. 
Table 3. Prevalence of Conditions of Interest Among Cases and Controls

\begin{tabular}{|c|c|c|c|c|}
\hline Conditions & $\begin{array}{c}\text { Cases } \\
(\mathrm{N}=6078)\end{array}$ & $\begin{array}{c}\text { Controls } \\
(\mathrm{N}=30,326)\end{array}$ & $\begin{array}{c}\text { Odds Ratio } \\
\text { (Cases:Controls) }\end{array}$ & $P$ \\
\hline \multicolumn{5}{|l|}{ Cancer conditions } \\
\hline Breast & $10(0.16 \%)$ & $246(0.81 \%)$ & $0.20(0.11,0.38)$ & $<0.0001^{*}$ \\
\hline Cervix & $38(0.63 \%)$ & $653(2.15 \%)$ & $0.29(0.21,0.40)$ & $<0.0001^{*}$ \\
\hline Testis & $10(0.16 \%)$ & $19(0.00 \%)$ & $2.63(1.22,5.66)$ & $0.0102^{*}$ \\
\hline Colorectal & $3(0.05 \%)$ & $115(0.38 \%)$ & $0.13(0.04,0.41)$ & $<0.0001^{*+}$ \\
\hline Leukemia & $50(0.82 \%)$ & $59(0.19 \%)$ & $4.26(2.92,6.21)$ & $<0.0001^{*}$ \\
\hline Lymphoma (Hodgkin's and non-Hodgkin's) & $11(0.18 \%)$ & $67(0.22 \%)$ & $0.82(0.43,1.55)$ & 0.5387 \\
\hline Melanomas of skin & $6(0.10 \%)$ & $59(0.19 \%)$ & $0.51(0.22,1.17)$ & 0.1063 \\
\hline \multicolumn{5}{|l|}{ Heart disease conditions } \\
\hline High blood pressure/hypertension & $345(5.68 \%)$ & $18,139(59.81 \%)$ & $0.04(0.04,0.05)$ & $<0.0001^{*}$ \\
\hline Late effects of cerebrovascular disease (stroke) & $36(0.59 \%)$ & $138(0.46 \%)$ & $1.30(0.90,1.88)$ & 0.1568 \\
\hline Coronary atherosclerosis and other heart disease & $109(1.80 \%)$ & $1035(3.41 \%)$ & $0.52(0.42,0.63)$ & $<0.0001^{*}$ \\
\hline Acute myocardial infarction & $40(0.66 \%)$ & $213(0.70 \%)$ & $0.94(0.67,1.31)$ & 0.7046 \\
\hline Moyamoya & $14(0.23 \%)$ & $4(0.00 \%)$ & $17.50(5.76,53.19)$ & $<0.0001^{*+}$ \\
\hline \multicolumn{5}{|l|}{ Mental health conditions } \\
\hline Anxiety & $850(13.98 \%)$ & $3757(12.39 \%)$ & $1.15(1.06,1.25)$ & $0.0006^{*}$ \\
\hline Obsessive-compulsive disorder & $445(7.32 \%)$ & $124(0.41 \%)$ & $19.24(15.74,23.53)$ & $<0.0001^{*}$ \\
\hline $\begin{array}{l}\text { Attention-deficit, conduct, disruptive } \\
\text { behavior disorders }\end{array}$ & $233(3.83 \%)$ & $1563(5.15 \%)$ & $0.73(0.64,0.84)$ & $<0.0001^{*}$ \\
\hline Mood disorders & $761(12.52 \%)$ & $3247(10.71 \%)$ & $1.19(1.10,1.30)$ & $<0.0001^{*}$ \\
\hline Schizophrenia and other psychoses & $99(1.63 \%)$ & $176(0,58 \%)$ & $2.84(2.21,3.63)$ & $<0.0001^{*}$ \\
\hline Impulse control disorders, NEC & $27(0.44 \%)$ & $34(0.11 \%)$ & $3.98(2.40,6.59)$ & $<0.0001^{*}$ \\
\hline Catatonia & $73(1.20 \%)$ & $70(0.23 \%)$ & $5.25(3.78,7.30)$ & $<0.0001^{*}$ \\
\hline \multicolumn{5}{|l|}{ Infections } \\
\hline STD (not including HIV or hepatitis) & $12(0.20 \%)$ & $304(1.00 \%)$ & $0.20(0.11,0.35)$ & $<0.0001^{*}$ \\
\hline HIV & $10(0.16 \%)$ & $105(0.35 \%)$ & $0.47(0.25,0.91)$ & $0.0212^{*}$ \\
\hline Hepatitis & $46(0.76 \%)$ & $217(0.72 \%)$ & $1.06(0.77,1.46)$ & 0.7288 \\
\hline Influenza & $125(2.06 \%)$ & $1004(3.31 \%)$ & $0.61(0.51,0.74)$ & $<0.0001^{*}$ \\
\hline Bronchitis & $210(3.46 \%)$ & $479(1.58 \%)$ & $2.23(1.89,2.63)$ & $<0.0001^{*}$ \\
\hline Sinusitis & $389(6.40 \%)$ & $4624(15.25 \%)$ & $0.38(0.34,0.42)$ & $<0.0001^{*}$ \\
\hline Pneumonia & $680(11.19 \%)$ & $964(3.18 \%)$ & $3.84(3.46,4.25)$ & $<0.0001^{*}$ \\
\hline Urinary tract infection & $286(4.71 \%)$ & $2068(6.82 \%)$ & $0.67(0.59,0.77)$ & $<0.0001^{*}$ \\
\hline Cellulitis & $480(7.90 \%)$ & $2344(7.73 \%)$ & $1.02(0.92,1.13)$ & 0.6550 \\
\hline \multicolumn{5}{|l|}{ Gastrointestinal conditions } \\
\hline Intestinal obstruction without hernia & $82(1.35 \%)$ & $167(5.51 \%)$ & $2.47(1.89,3.22)$ & $<0.0001^{*}$ \\
\hline Esophageal disorders & $1054(17.34 \%)$ & $3679(12.13 \%)$ & $1.52(1.41,1.64)$ & $<0.0001^{*}$ \\
\hline Gastroduodenal ulcer except hemorrhage & $71(1.17 \%)$ & $249(0.82 \%)$ & $1.43(1.10,1.86)$ & $0.0082^{*}$ \\
\hline Celiac & $328(5.40 \%)$ & $93(0.31 \%)$ & $18.54(14.70,23.39)$ & $<0.0001^{*}$ \\
\hline \multicolumn{5}{|l|}{ Endocrine conditions } \\
\hline Thyroid & $2362(38.86 \%)$ & $2282(7.52 \%)$ & $7.81(7.31,8.35)$ & $<0.0001^{*}$ \\
\hline Diabetes & $630(10.37 \%)$ & $4011(13.23 \%)$ & $0.76(0.69,0.83)$ & $<0.0001^{*}$ \\
\hline \multicolumn{5}{|l|}{ Neurology conditions } \\
\hline Epilepsy; convulsions & $804(13.23 \%)$ & $878(2.90 \%)$ & $5.11(4.63,5.65)$ & $<0.0001^{*}$ \\
\hline Alzheimer's disease & $739(12.16 \%)$ & $114(0.38 \%)$ & $36.68(30.05,44.78)$ & $<0.0001^{*}$ \\
\hline Myelopathy, cervical & $51(0.84 \%)$ & $102(0.34 \%)$ & $2.51(1.79,3.51)$ & $<0.0001^{*}$ \\
\hline \multicolumn{5}{|l|}{ Orthopedic conditions } \\
\hline Atlantoaxial subluxation & $137(2.25 \%)$ & $9(0.00 \%)$ & $77.68(39.55,152.57)$ & $<0.0001^{*}$ \\
\hline Osteoporosis & $12(0.20 \%)$ & $26(0.09 \%)$ & $2.31(1.16,4.57)$ & $0.0138^{*}$ \\
\hline Osteoarthritis & $380(6.25 \%)$ & $1841(6.07 \%)$ & $1.03(0.92,1.16)$ & 0.5898 \\
\hline \multicolumn{5}{|l|}{ Miscellaneous conditions } \\
\hline Dysphagia & $824(13.56 \%)$ & $743(2.45 \%)$ & $6.24(5.63,6.92)$ & $<0.0001^{*}$ \\
\hline Diseases of the eyes and adnexa & $1710(28.13 \%)$ & $6177(20.37 \%)$ & $1.53(1.44,1.63)$ & $<0.0001^{*}$ \\
\hline Diseases of the ears and mastoid process & $2484(40.87 \%)$ & $8117(26.77 \%)$ & $1.89(1.79,2.00)$ & $<0.0001^{*}$ \\
\hline Sleep apnea & $581(9.56 \%)$ & $1713(5.65 \%)$ & $1.77(1.60,1.95)$ & $<0.0001^{*}$ \\
\hline
\end{tabular}

*Statistically significant based on alpha of 0.05 .

${ }^{\dagger}$ Fisher's exact test was interpreted. All other P-values interpreted by Pearson's chi-squared test.

NEC, not elsewhere classified; STD, sexually transmitted disease. 
Institute Inc.). All analysis of the sample data was performed by research personnel at Advocate Lutheran General Hospital (Park Ridge, IL).

\section{RESULTS}

Case population was predominantly White $(77.35 \%)$ and of non-Hispanic ethnicity $(73.51 \%)$. Cases in the data set had a median of 6 total encounters (ie, clinical visits in the health system). Controls in the data set were predominantly White $(61.97 \%)$, of nonHispanic ethnicity $(81.72 \%)$, and had a median of 7 total encounters. Cases and controls were matched on sex and year of birth, with both groups approximately $52 \%$ male and (median) 25.0 years old. Table 2 displays the demographics of the DS sample and the matched control sample.

The following results will describe OR associated with statistically significant P-values when comparing prevalence of clinical conditions of interest among cases to matched controls, specifically related to cancer, heart disease, mental health, infections, and gastrointestinal, endocrine, neurological, orthopedic, and other miscellaneous conditions. See Table 1 for a full list of the specific conditions of interest within these broad categories and Table 3 for full results and P-values.

\section{Cancer Conditions}

Relative to controls, cases had greater odds of experiencing testicular cancer (OR: 2.63 [1.22, 5.66]) and leukemia (OR: 4.26 [2.92, 6.21]). Relative to controls, cases had lesser odds of experiencing breast (OR: 0.20 [0.11, 0.38]), cervical (OR: 0.29 [0.21, 0.40]), and colorectal (OR: $0.13[0.04,0.41])$ cancers. There was not a statistically significant difference in OR for melanoma or lymphoma.

\section{Heart Disease Conditions}

Relative to controls, cases had greater odds of experiencing moyamoya disease, a chronic and progressive condition resulting in narrowing of the arteries in the brain (OR: 17.50 [5.76, 53.19]). Relative to controls, cases had lesser odds of experiencing hypertension (OR: 0.04 [0.04, 0.05]) and coronary atherosclerosis or other heart disease (OR: 0.52 [0.42, $0.63])$. There was not a statistically significant difference in OR for acute myocardial infarction or stroke.

\section{Mental Health Conditions}

Relative to controls, cases had greater odds of experiencing anxiety (OR: 1.15 [1.06, 1.25]), obsessivecompulsive disorder (OR: 19.24 [15.74, 23.53]), mood disorders (OR: 1.19 [1.10, 1.30]), schizophrenia or other psychoses (OR: 2.84 [2.21, 5.63]), impulse control disorders (OR: 3.98 [2.40, 6.59]), and catatonia (OR: 5.25 $[3.78,7.30])$. Relative to controls, cases had lesser odds of experiencing attention-deficit, conduct, or disruptive behavior disorders (OR: 0.73 [0.64, 0.84]).

\section{Infections}

Relative to controls, cases had greater odds of experiencing bronchitis (OR: 2.23 [1.89, 2.63]) and pneumonia (OR: 3.84 [3.46, 4.25]). Relative to controls, cases had lesser odds of experiencing sexually transmitted diseases (OR: 0.20 [0.11, 0.35]), HIV (OR: 0.47 [0.25, 0.91]), influenza (OR: 0.61 [0.51, 0.74]), sinusitis (OR: 0.38 [0.34, 0.42]), and urinary tract infections (OR: $0.67[0.59,0.77])$. There was not a statistically significant difference in OR for cellulitis or hepatitis.

\section{Gastrointestinal Conditions}

Relative to controls, cases had greater odds of experiencing intestinal obstruction without hernia (OR: $2.47[1.89,3.22])$, esophageal disorders (OR: 1.52 [1.41, $1.64]$ ), gastroduodenal ulcers (OR: $1.43[1.10,1.86])$, and celiac disease (OR: 18.54 [14.70, 23.39]).

\section{Endocrine Conditions}

Relative to controls, cases had greater odds of experiencing thyroid disorders (OR: 7.81 [7.31, 8.35]). Relative to controls, cases had lesser odds of experiencing diabetes (OR: $0.76[0.69,0.83])$.

\section{Neurology Conditions}

Relative to controls, cases had greater odds of experiencing epilepsy convulsions (OR: 5.11 [4.63, 5.65]), Alzheimer's disease (OR: 36.68 [30.05, 44.78]), and cervical myelopathy (OR: $2.51[1.79,3.51])$.

\section{Orthopedic Conditions}

Relative to controls, cases had greater odds of experiencing atlantoaxial subluxation (OR: $77.68[39.55,152.57])$ and osteoporosis (OR: 2.31 [1.16, 4.57]). There was not a statistically significant difference in OR for osteoarthritis.

\section{Miscellaneous Conditions}

Relative to controls, cases had greater odds of experiencing dysphagia (OR: 6.24 [5.63, 6.92]), diseases of the eye and adnexa (OR: $1.53[1.44,1.63])$, diseases of the ears and mastoid process (OR: $1.89[1.79,2.00])$, and sleep apnea (OR: $1.77[1.60,1.95])$.

\section{DISCUSSION}

Based on our review of the literature, this study reports on one of the largest cohorts of individuals with DS with matching controls in the United States. The prevalence 
of nearly all conditions of interest in this study were statistically significantly higher or lower in individuals with DS compared to the control population. Our findings support similar data of this range and magnitude available from the United Kingdom. ${ }^{12}$ This section will look at this study's findings for each condition category separately for clarification.

\section{Cancer}

Our U.S.-based results support previous research documenting increased leukemias among individuals with DS, 14,20,26,27 increased testicular cancer among males with DS, ${ }^{14}$ and lower prevalence of solid tumors (ie, breast, cervix, colorectal) among individuals with DS relative to non-DS counterparts. ${ }^{14,28}$ It should be noted that, while the prevalence of colorectal cancer in this study is low, the data on colorectal cancer are mixed, suggesting inconveniences versus benefits of colonoscopy - the American standard for screening be weighed more carefully in this group. ${ }^{27}$ Given barriers to examining for cancers among individuals with DS, future research could explore the extent to which fewer examinations and subsequent diagnosis of cancer may be responsible for low prevalence of cancers observed among individuals with DS.

\section{Heart Disease}

Since congenital heart disease is well documented as more prevalent in individuals with $\mathrm{DS},{ }^{29-31}$ our study did not explore it. As expected, hypertension, coronary atherosclerosis, and other heart disease were significantly lower in individuals with DS relative to non-DS counterparts. ${ }^{12,15,16}$ Prevalence differences in acute myocardial infarction and stroke were both considered nonsignificant. Regarding myocardial infarction, it should be noted that this study's cases and controls were matched on age, with medians of 25 years and means of 28 years, so it is not a surprising that rate of myocardial infarction was low in both groups and nonsignificant. Further study is required to explain the lower prevalence of atherosclerotic heart disease but similar prevalence of acute myocardial infarction among individuals with DS. While similar relative prevalence would be expected, increased congenital heart disease or sleep apnea among individuals with DS could have increased myocardial infarction events in this sample. ${ }^{12,32-35}$

Regarding stroke, while individuals with DS experienced more stroke clinically, the difference was not significant. Prior research has suggested that increased stroke risk is moderated by cardioembolic risk (eg, congenital heart disease, cardiac arrythmia), ${ }^{15}$ but this study did not explore these additional risk factors. Increased stroke may be explained partly by the higher prevalence of congenital heart disease common among individuals with $\mathrm{DS}^{15}$ or due to the higher prevalence of moyamoya disease reflected in our DS sample.

\section{Mental Health Conditions}

Overall, individuals with DS were more likely than their non-DS counterparts to experience a wide variety of mental health conditions, including anxiety, obsessivecompulsive disorder, mood disorders (major depression and bipolar disorder), schizophrenia and other psychoses, impulse control disorders, and catatonia. While anxiety and mood disorders ${ }^{36-38}$ and obsessivecompulsive disorder ${ }^{39}$ have been documented as more common among individuals with DS, bipolar disorder has been documented as less common. ${ }^{40}$ It should be noted that our study looked at mood disorder broadly, as bipolar disorder and depression, finding it more prevalent among individuals with DS relative to nonDS counterparts. Catatonia was more prevalent in our sample of individuals with DS, but catatonia has only recently been recognized in individuals with $\mathrm{DS} ;{ }^{41-43}$ thus, there are no previous data of which we are aware regarding its prevalence.

In our cohort, attention-deficit, conduct, and disruptive behavior disorders were found to be less prevalent among individuals with DS relative to non-DS counterparts. Prior research that did not use a comparison group has shown it to be highly prevalent. ${ }^{44,45}$ Additionally, it has been noted that diagnosis of these types of behavior conditions can be inaccurate ${ }^{45,46}$ given common symptoms, like sensory deficits caused by other comorbid medical conditions. ${ }^{45}$ Contrary to one prior study, ${ }^{40}$ we found a higher prevalence of schizophrenia in individuals with DS. Research has noted that schizophrenia and psychoses may be overdiagnosed in people with intellectual disabilities due to symptoms associated with mood disorders or other mental health conditions that are misinterpreted as psychoses. ${ }^{47}$ Overall, individuals with DS are more vulnerable to mental health issues and also more diagnoses, due to deficits in language, communication, cognition, problem-solving, and coping, ${ }^{48}$ and there is limited literature on the diagnosis of psychiatric comorbidities among this group. ${ }^{49}$

Due to the diagnostic challenges and limited literature, we recommend cautious interpretation of mental illness data in individuals with DS. Future research should attempt to mitigate these challenges. 


\section{Infections}

Individuals with DS had lower prevalence of sexually transmitted diseases, HIV, and urinary tract infections, which could be due to less sexual activity contributed to by noted delays in sexual maturity. ${ }^{50}$ However, there is limited data on sexual activity of individuals with intellectual disabilities, including individuals with DS, and data are often reported by caregivers rather than the individual with DS. ${ }^{51-53}$

Specific to respiratory infections, individuals with DS had lower prevalence of influenza and sinusitis but, consistent with other findings, higher prevalence of bronchitis and pneumonia. ${ }^{54-56}$ Immune defects, airway anatomical abnormalities, and an inability to handle secretions have been noted to explain increased infections among individuals with DS. ${ }^{54}$ The higher prevalence of dysphagia noted among individuals with DS in our sample could be contributing to the increased pneumonia seen in our and previously reported studies. ${ }^{10,57}$ Furthermore, encounter-level provider documentation habits also may explain discrepancies; specifically, if a more severe condition (eg, bronchitis, pneumonia) is diagnosed, then less severe conditions (eg, influenza, sinusitis) may be left undocumented. Additional research to understand prevalence of varying infections is necessary.

\section{Gastrointestinal Conditions}

Our research found that individuals with DS are more likely to experience a variety of gastrointestinal conditions, including intestinal obstructions, esophageal disorders, gastroduodenal ulcers, and celiac disease. This supports extensive prior research documenting more common structural and functional disorders of the gastrointestinal tract among individuals with DS. ${ }^{12,58-63}$

\section{Endocrine Conditions}

Individuals with DS had higher prevalence of thyroid disorder relative to non-DS counterparts. Hypothyroidism and hyperthyroidism are known to be more prevalent among individuals with DS than individuals without DS., ${ }^{9,264}$ Our study found that individuals with DS had lower prevalence of diabetes mellitus relative to non-DS counterparts. Other studies have shown an increased prevalence of type I diabetes among individuals with DS. ${ }^{64,65}$ Previous data are less clear on prevalence of type II diabetes, with studies showing increased, similar, and decreased rates compared with individuals without DS. ${ }^{10,64}$ The coding framework used in this study did not separate ICD codes by type, so this study did not explore thyroid disorder or diabetes by type.

\section{Neurological Conditions}

Our findings corroborate prior research that individuals with DS experience more epilepsy convulsions, Alzheimer's disease, and cervical myelopathy relative to non-DS counterparts. ${ }^{12,66,67}$ Higher prevalence of epilepsy and related seizures and Alzheimer's disease type of dementia have been documented in individuals with DS, ${ }^{18,68-70}$ separately and also as associated conditions. ${ }^{71}$ Cervical myelopathy is often caused by compression of the spinal cord, which may be associated with the increased prevalence of atlantoaxial subluxation seen in our DS sample. ${ }^{72}$

\section{Orthopedic Conditions}

As mentioned, we found that individuals with DS experience more atlantoaxial subluxation relative to non-DS counterparts. The prevalence of osteoporosis also was higher among individuals with DS in our sample, which is consistent with data from other studies. ${ }^{13,73}$ Further study is needed to understand the significance of this finding. It has been suggested that bone density scans may not be as accurate in individuals with DS due to bone length differences between those with and without DS. ${ }^{74} \mathrm{~A}$ more recent study adjusted for bone length differences and found that individuals with DS, especially men, had lower volumetric bone mineral density. ${ }^{75}$ We could not identify research on fracture rates associated with osteoporosis in individuals with DS specifically; thus, the clinical significance of osteoporosis is unclear.

\section{Miscellaneous Conditions}

Finally, our study indicated that individuals with DS are more likely to experience a number of miscellaneous conditions focused on sense organs and other organs in the head and neck, including dysphagia, diseases of the eye and adnexa, diseases of the ears and mastoid process, and sleep apnea. This has been supported by prior research. ${ }^{9,10,12,13,66}$ As suggested in the infections subsection, it is possible that airway anatomical abnormalities could contribute to increased prevalence of these conditions, too. ${ }^{54}$

\section{Strengths and Limitations}

This study is one of the largest to date overall, and particularly in the United States, to investigate the prevalence of comorbidities in individuals with DS, making it suitable for the analysis of relatively rare morbidities of interest. Our data set incorporated the earliest available data, which represented 28 years of patient data and allowed for a very comprehensive look at prevalence. Our analysis also included a large group of controls matched by age and sex, a sample that could 
be representative of non-DS patients in U.S. health care. As our goal was to compare individuals with DS to a large sample of controls representative of the population of hospital patients, matching across all pertinent demographic factors would have been ideal; however, we chose not to match on race or body mass index (BMI), as neither are well- or accurately captured variables in most medical records. Furthermore, adjusting for race or BMI would have likely resulted in selection bias, as race is collected differently by group and BMI is only collected at certain visit types (ie, inpatient) within our health system. We plan to consider these variables in future analyses.

While these findings represent data from only one health system, this large integrated system may provide the most accurate and available review of prevalence among a U.S.-based cohort, given the country's fragmented storage of data. Furthermore, much of this data set comes from a specialized care center specifically serving adults with DS, which may improve diagnostic accuracy of ICD coding and subsequent prevalence findings. A minority of the data set comes from other system sites less familiar with serving adults with DS, potentially affecting diagnostic consistency. While life expectancy has increased rapidly over the past few decades, it has seemed to plateau in recent years, reducing the potential for change in identified common comorbid conditions. ${ }^{76}$

It should be noted that diagnostic accuracy in general can be difficult with individuals with DS for a variety of reasons. ${ }^{77}$ Additionally, observed prevalence among patients receiving only specialty care versus primary care within the health system could be different. Also, observed prevalence within patients with DS, particularly by level of function or intelligence, could be different. However, these designations were too difficult to parse out in this study.

While this study utilized an established coding framework of ICD-9 diagnosis codes to represent the conditions of interest specifically for research, ${ }^{25}$ it is acknowledged that these codes may not be ones most commonly used to diagnose comorbid conditions among individuals with DS, introducing potential for underrepresentation of conditions. It is also possible that these particular codes could be used to diagnose individuals with DS more or less than individuals without DS. It is also possible that conditions coded among one single patient could be due to error instead of reality.

\section{Future Research}

We looked at all individuals with DS, including youth and adults, and reported prevalence of conditions among them relative to controls. The types of comorbid conditions, as well as the pattern of occurrence over time, have been noted as different. It is important to highlight the fact that this paper does not explore differences in examination for or diagnosis of health conditions, and it is certainly possible that inequalities exist due to inherent differences in individuals with and without DS. Future analyses should consider looking at prevalence of conditions among individuals with DS relative to individuals without DS but with more comparable intellectual and/or developmental disabilities. Youth and adults should be looked at separately and across time to track the course of conditions seen at difference stages of the increasing lifespan of individuals with DS.

While these prevalence findings are a jumping-off point for remodeled care specific to individuals with DS, they also compel new research. For one, a deeper investigation into the broad range of highly prevalent mental health conditions is merited. Comorbid mental and physical health conditions likely impact treatment progress in both areas, so understanding the relationship between them is critical in this group. Furthermore, the varied prevalence of infections warrants further exploration into differences in how individuals with DS experience infections. Finally, further analysis of endocrine disorders, specifically thyroid disorder and diabetes, is required to better understand if certain condition subtypes are driving prevalence findings.

\section{CONCLUSIONS}

This study describes prevalence of clinical conditions assessed by comparing total unique cases and controls, respectively, with at least one AHRQ ICD-9 code in each category in any encounter in a large health system's electronic medical records. Our findings show that observed prevalence of comorbid conditions seen in individuals with Down syndrome are vastly different compared to their non-DS-matched counterparts. While it is a challenge to draw widespread conclusions about comorbidities in individuals with DS, generally speaking, it is safe to conclude that care for individuals with DS should not automatically mirror screening, prevention, or treatment guidelines for the general U.S. population. Instead, care for those with DS should reflect the unique needs and common comorbidities of this population. 


\section{Patient-Friendly Recap}

- People with Down syndrome are living longer than in decades past and thus more susceptible to longer durations of unique health problems.

- Authors reviewed data from an exceptionally large Down syndrome cohort to compare a litany of diagnoses to a general U.S.-based patient population matched for age and sex.

- Individuals with Down syndrome were more likely to be diagnosed with testicular or blood cancer, mental health conditions, bronchitis, pneumonia, and gastrointestinal, neurological, thyroid, and bone diseases, among others. They were less likely to be diagnosed with solid tumors, heart disease, sexually transmitted disease, influenza, sinusitis, and diabetes.

- Health care for those with Down syndrome should reflect the unique needs and commonly occurring conditions of this population.

\section{Author Contributions}

Study design: Chicoine, Rzhetsky. Data acquisition or analysis: Chicoine, Rivelli, Fitzpatrick. Manuscript drafting: all authors. Critical revision: all authors.

\section{Conflicts of Interest}

None.

\section{Funding Sources}

This work was funded in part by a National Institutes of Health award (\#3UL1TR002389-03S1).

\section{References}

1. Kazemi M, Salehi M, Kheirollahi M. Down syndrome: current status, challenges and future perspectives. Int J Mol Cell Med. 2016;5:125-33.

2. Centers for Disease Control and Prevention. Facts about Down syndrome. Last reviewed December 28, 2020; accessed November 1, 2020. https://www.cdc.gov/ncbddd/birthdefects/ downsyndrome.html\#ref

3. Glasson EJ, Sullivan SG, Hussain R, Petterson BA, Montgomery PD, Bittles AH. The changing survival profile of people with Down's syndrome: implications for genetic counselling. Clin Genet. 2002;62:390-3. CrossRef

4. National Down Syndrome Society. Down syndrome facts. Accessed November 1, 2020. https://www.ndss.org/aboutdown-syndrome/down-syndrome-facts/

5. Bittles AH, Glasson EJ. Clinical, social, and ethical implications of changing life expectancy in Down syndrome. Dev Med Child Neurol. 2004;46:282-6. CrossRef

6. Coppus AM, Evenhuis HM, Verberne GJ, et al. Survival in elderly persons with Down syndrome. J Am Geriatr Soc. 2008;56:2311-6. CrossRef
7. Zhu JL, Hasle H, Correa A, et al. Survival among people with Down syndrome: a nationwide population-based study in Denmark. Genet Med. 2013;15:64-9. CrossRef

8. Mai CT, Isenburg JL, Canfield MA, et al. National populationbased estimates for major birth defects, 2010-2014. Birth Defects Res. 2019;111:1420-35. CrossRef

9. Capone GT, Chicoine B, Bulova P, et al. Co-occurring medical conditions in adults with Down syndrome: a systematic review toward the development of health care guidelines. $\mathrm{Am}$ J Med Genet A. 2018;176:116-33. CrossRef

10. Capone G, Stephens M, Santoro S, et al. Co-occurring medical conditions in adults with Down syndrome: a systematic review toward the development of health care guidelines. Part II. Am J Med Genet A. 2020;182:1832-45. CrossRef

11. Bittles AH, Bower C, Hussain R, Glasson EJ. The four ages of Down syndrome. Eur J Public Health. 2007;17:221-5. CrossRef

12. Alexander M, Petri H, Ding Y, Wandel C, Khwaja O, Foskett N. Morbidity and medication in a large population of individuals with Down syndrome compared to the general population. Dev Med Child Neurol. 2016;58:246-54. CrossRef

13. Kinnear D, Morrison J, Allan L, Henderson A, Smiley E, Cooper SA. Prevalence of physical conditions and multimorbidity in a cohort of adults with intellectual disabilities with and without Down syndrome: cross-sectional study. BMJ Open. 2018;8(2):e018292. CrossRef

14. Hasle H, Friedman JM, Olsen JH, Rasmussen SA. Low risk of solid tumors in persons with Down syndrome. Genet Med. 2016;18:1151-7. CrossRef

15. Sobey CG, Judkins CP, Sundararajan V, Phan TG, Drummond GR, Srikanth VK. Risk of major cardiovascular events in people with Down syndrome. PLoS One. 2015;10(9):e137093. CrossRef

16. Fitzpatrick V, Rivelli A, Bria K, Chicoine B. Heart disease in adults with Down syndrome between 1996 and 2016. J Am Board Fam Med. 2020;33:923-31. CrossRef

17. Lavigne J, Sharr C, Elsharkawi I, et al. Thyroid dysfunction in patients with Down syndrome: results from a multi-institutional registry study. Am J Med Genet A. 2017;173:1539-45. CrossRef

18. Rubenstein E, Hartley S, Bishop L. Epidemiology of dementia and Alzheimer disease in individuals with Down syndrome. JAMA Neurol. 2020;77:262-4. CrossRef

19. Lee CF, Lee CH, Hsueh WY, Lin MT, Kang KT. Prevalence of obstructive sleep apnea in children with Down syndrome: a meta-analysis. J Clin Sleep Med. 2018;14:867-75. CrossRef

20. Sullivan SG, Hussain R, Glasson EJ, Bittles AH. The profile and incidence of cancer in Down syndrome. J Intellect Disabil Res. 2007;51(Pt 3):228-31. CrossRef

21. Quantin C, Jaquet-Chiffelle DO, Coatrieux G, Benzenine E, Auverlot B, Allaert FA. Medical record: systematic centralization versus secure on demand aggregation. BMC Med Inform Decis Mak. 2011;11:18. CrossRef

22. Rall T. The U.S. also needs a centralized medical system. The Japan Times. [May 12, 2020]. Accessed November 1, 2020. https:/www.japantimes.co.jp/opinion/2020/05/12/commentary/ world-commentary/u-s-also-needs-centralized-medical-system/

23. National Down Syndrome Society. Healthcare guidelines. Accessed November 1, 2020. https://www.ndss.org/resources/ healthcare-guidelines/ 
24. Tsou AY, Bulova P, Capone G, et al. Medical care of adults with Down syndrome: a clinical guideline. JAMA. 2020;324:1543-56. CrossRef

25. Agency for Healthcare Research and Quality. Clinical Classification Software (CCS) for ICD-9-CM. Last modified March 6, 2017; accessed October 1, 2019. https://www.hcupus.ahrq.gov/toolssoftware/ccs/ccs.jsp

26. Zeller B, Gustafsson G, Forestier E, et al. Acute leukaemia in children with Down syndrome: a population-based Nordic study. Br J Haematol. 2005;128:797-804. CrossRef

27. Rethoré MO, Rouëssé J, Satgé D. Cancer screening in adults with down syndrome, a proposal. Eur J Med Genet. 2020;63(4):103783. CrossRef

28. Hasle H, Clemmensen IH, Mikkelsen M. Risks of leukaemia and solid tumours in individuals with Down's syndrome. Lancet. 2000;355:165-9. CrossRef

29. Hartman RJ, Rasmussen SA, Botto LD, et al. The contribution of chromosomal abnormalities to congenital heart defects: a population-based study. Pediatr Cardiol. 2011;32:1147-57. CrossRef

30. Pierpont ME, Brueckner M, Chung WK, et al. Genetic basis for congenital heart disease: revisited: a scientific statement from the American Heart Association. Circulation. 2018;138:e653-711. CrossRef

31. Versacci P, Di Carlo D, Digilio MC, Marino B. Cardiovascular disease in Down syndrome. Curr Opin Pediatr. 2018;30:616-22. CrossRef

32. von Känel R, Princip M, Schmid JP, et al. Association of sleep problems with neuroendocrine hormones and coagulation factors in patients with acute myocardial infarction. $B M C$ Cardiovasc Disord. 2018;18(1):213. CrossRef

33. Jegatheeswaran A, Devlin PJ, McCrindle BW, et al. Features associated with myocardial ischemia in anomalous aortic origin of a coronary artery: a Congenital Heart Surgeons' Society study. J Thorac Cardiovasc Surg. 2019;158:822-34.e3. CrossRef

34. Randerath W, Bonsignore MR, Herkenrath S. Obstructive sleep apnoea in acute coronary syndrome. Eur Respir Rev. 2019;28(153):180114. CrossRef

35. Wang T, Chen L, Yang T, et al. Congenital heart disease and risk of cardiovascular disease: a meta-analysis of cohort studies. J Am Heart Assoc. 2019;8(10):e012030. CrossRef

36. Mantry D, Cooper SA, Smiley E, et al. The prevalence and incidence of mental ill-health in adults with Down syndrome. J Intellect Disabil Res. 2008;52(Pt 2):141-55. CrossRef

37. Haveman M, Heller T, Lee L, Maaskant M, Shooshtari $\mathrm{S}$, Strydom A. Major health risks in aging persons with intellectual disabilities: an overview of recent studies. J Policy Pract Intellect Disabil. 2010;7:59-69. CrossRef

38. Stancliffe RJ, Lakin KC, Larson SA, et al. Demographic characteristics, health conditions, and residential service use in adults with Down syndrome in 25 U.S. states. Intellect Dev Disabil. 2012;50:92-108. CrossRef

39. Prasher VP. Prevalence of psychiatric disorders in adults with Down syndrome. Eur J Psychiatry. 1995;9:77-82.

40. Dykens EM. Psychiatric and behavioral disorders in persons with Down syndrome. Ment Retard Dev Disabil Res Rev. 2007;13:272-8. CrossRef

41. Ghaziuddin N, Nassiri A, Miles JH. Catatonia in Down syndrome; a treatable cause of regression. Neuropsychiatr Dis Treat. 2015;11:941-9. CrossRef
42. Miles JH, Takahashi N, Muckerman J, Nowell KP, Ithman M. Catatonia in Down syndrome: systematic approach to diagnosis, treatment and outcome assessment based on a case series of seven patients. Neuropsychiatr Dis Treat. 2019;15:2723-41. CrossRef

43. Chicoine B, Capone G. Regression in adolescents and adults with Down syndrome. In: Prasher VP, Janicki MP (eds). Physical Health of Adults with Intellectual and Developmental Disabilities, Second Edition. Springer Nature Switzerland; 2019, pp. 121-40.

44. Määttä T, Tervo-Määttä T, Taanila A, Kaski M, Iivanainen M. Mental health, behaviour and intellectual abilities of people with Down syndrome. Downs Syndr Res Pract. 2006;11:37-43. CrossRef

45. Ekstein S, Glick B, Weill M, Kay B, Berger I. Down syndrome and attention-deficit/hyperactivity disorder (ADHD). J Child Neurol. 2011;26:1290-5. $\underline{\text { CrossRef }}$

46. National Down Syndrome Society. ADHD \& Down syndrome. Accessed November 3, 2020. https://www.ndss.org/resources/ adhd-down-syndrome/

47. Pary RJ, Loschen EL, Tomkowiak SB. Mood disorders and Down syndrome. Semin Clin Neuropsychiatry. 1996;1:148-53.

48. National Down Syndrome Society. Mental health issues \& Down syndrome. Accessed November 3, 2020. https://www. ndss.org/resources/mental-health-issues-syndrome/

49. Palumbo ML, McDougle CJ. Pharmacotherapy of Down syndrome. Expert Opin Pharmacother. 2018;19:1875-89. CrossRef

50. National Down Syndrome Society. Sexuality. Accessed November 3, 2020. https://www.ndss.org/resources/ sexuality/\#: : text=Men $\% 20$ and $\% 20$ women $\% 20$ with $\% 20$ Down, and $\% 20$ other $\% 20$ sexually $\% 20$ transmitted $\% 20$ infections

51. Eastgate G, Scheermeyer E, van Driel ML, Lennox N. Intellectual disability, sexuality and sexual abuse prevention - a study of family members and support workers. Aust Fam Physician. 2012;41:135-9.

52. Medina-Rico M, López-Ramos H, Quiñonez A. Sexuality in people with intellectual disability: review of literature. Sex Disabil. 2018;36:231-48. CrossRef

53. Schmidt EK, Hand BN, Simpson KN, Darragh AR. Sexually transmitted infections in privately insured adults with intellectual and developmental disabilities. J Comp Eff Res. 2019;8:599-606. CrossRef

54. Ram G, Chinen J. Infections and immunodeficiency in Down syndrome. Clin Exp Immunol. 2011;164:9-16. CrossRef

55. O'Leary L, Hughes-McCormack L, Dunn K, Cooper SA. Early death and causes of death of people with Down syndrome: a systematic review. J Appl Res Intellect Disabil. 2018;31:687-708. CrossRef

56. Santoro SL, Chicoine B, Jasien JM, et al. Pneumonia and respiratory infections in Down syndrome: a scoping review of the literature. Am J Med Genet A. 2021;185:286-99. CrossRef

57. Lazenby T. The impact of aging on eating, drinking, and swallowing function in people with Down's syndrome. Dysphagia. 2008;23:88-97. CrossRef

58. Buchin PJ, Levy JS, Schullinger JN. Down's syndrome and the gastrointestinal tract. J Clin Gastroenterol. 1986;8:111-4. CrossRef

59. Holmes G. Gastrointestinal disorders in Down syndrome. Gastroenterol Hepatol Bed Bench. 2014;7(1):6-8. 
60. Zárate N, Mearin F, Hidalgo A, Malagelada JR. Prospective evaluation of esophageal motor dysfunction in Down's syndrome. Am J Gastroenterol. 2001;96:1718-24. CrossRef

61. Friedmacher F, Puri P. Hirschsprung's disease associated with Down syndrome: a meta-analysis of incidence, functional outcomes and mortality. Pediatr Surg Int. 2013;29:937-46. CrossRef

62. Mårild K, Stephansson O, Grahnquist L, Cnattingius S, Söderman G, Ludvigsson JF. Down syndrome is associated with elevated risk of celiac disease: a nationwide case-control study. J Pediatr. 2013;163:237-42. CrossRef

63. Ravel A, Mircher C, Rebillat AS, Cieuta-Walti C, Megarbane A. Feeding problems and gastrointestinal diseases in Down syndrome. Arch Pediatr. 2020;27:53-60. CrossRef

64. Uppal H, Chandran S, Potluri R. Risk factors for mortality in Down syndrome. J Intellect Disabil Res. 2015;59:873-81. CrossRef

65. Guaraldi F, Giaccherino RR, Lanfranco F, et al. Endocrine autoimmunity in Down's syndrome. Front Horm Res. 2017;48:133-46. CrossRef

66. Antonarakis SE, Skotko BG, Rafii MS, et al. Down syndrome. Nat Rev Dis Primers. 2020;6(1):9. CrossRef

67. Ali FE, Al-Bustan MA, Al-Busairi WA, Al-Mulla FA, Esbaita EY. Cervical spine abnormalities associated with Down syndrome. Int Orthop. 2006;30:284-9. CrossRef

68. Rahman MM, Fatema K. Seizures in Down syndrome: an update. Mymensingh Med J. 2019;28:712-15.

69. Startin CM, D'Souza H, Ball G, et al. Health comorbidities and cognitive abilities across the lifespan in Down syndrome. J Neurodev Disord. 2020;12(1):4. CrossRef
70. Glasson EJ, Dye DE, Bittles AH. The triple challenges associated with age-related comorbidities in Down syndrome. J Intellect Disabil Res. 2014;58:393-8. CrossRef

71. Menéndez M. Down syndrome, Alzheimer's disease and seizures. Brain Dev. 2005;27:246-52. CrossRef

72. Mik G, Gholve PA, Scher DM, Widmann RF, Green DW. Down syndrome: orthopedic issues. Curr Opin Pediatr. 2008;20:30-6. CrossRef

73. Kerins G, Petrovic K, Bruder MB, Gruman C. Medical conditions and medication use in adults with Down syndrome: a descriptive analysis. Downs Syndr Res Pract. 2008;12:141-7. CrossRef

74. Kanis JA, Harvey NC, Johansson H, Odén A, Leslie WD, McCloskey EV. FRAX update. $J$ Clin Densitom. 2017;20:360-7. CrossRef

75. García Hoyos M, Humbert L, Salmón Z, Riancho JA, Valero C. Analysis of volumetric BMD in people with Down syndrome using DXA-based 3D modeling. Arch Osteoporos. 2019;14(1):98. CrossRef

76. Torr J, Strydom A, Patti P, Jokinen N. Aging in Down syndrome: morbidity and mortality. $J$ Policy Pract Intellect Disabil. 2010;7:70-81. CrossRef

77. Smith DS. Health care management of adults with Down syndrome. Am Fam Physician. 2001;64:1031-8.

(C) 2021 Advocate Aurora Health, Inc.

\title{
CME Accreditation and Credit Designation Statements
}

\author{
Advocate Aurora Health is accredited by the Accreditation Council for Continuing \\ Medical Education (ACCME) to provide continuing medical education for \\ physicians. Advocate Aurora designates this journal-based CME article for a \\ maximum of 1.00 AMA PRA Category 1 credit $^{\text {TM }}$. Physicians should claim only the \\ credit commensurate with the extent of their participation in the activity.
}

To earn CME credit for this article, visit https://cme.advocateaurorahealth.org/ content/prevalence-common-disease-conditions-large-cohort-individuals-downsyndrome-united-states to access and complete the online quiz. 